\title{
Behavioral and Neurochemical Changes Produced by Postnatal Pretreatments with Methamphetamine in Rats
}

\author{
Tetsu HAYASHI, Mineo KUNIHARA and Sakutaro TADOKORO \\ Behavioral Research Institute. Gunma University School of Medicine. \\ Maebashi 371 , Japan
}

Accepted September 22, 1986

\begin{abstract}
Male neonates of Wistar strain rats were given s.c. $1-4 \mathrm{mg} / \mathrm{kg} / \mathrm{day}$ of methamphetamine (MAP) for 7 successive days from days 6 to 12 after birth. The acquisition processes of the discriminative lever-press avoidance response were investigated from day 60 after birth. Effects of the postnatal pretreatments with MAP on saturation constants for specific bindings of ${ }^{3} \mathrm{H}$-spiperone (SPP) and ${ }^{3} \mathrm{H}$-WB4101, respectively, in 8 brain regions were also investigated at $100-120$ days after birth. In addition, dopamine, noradrenaline and the levels of their metabolites were measured in the brain. No significant difference was detected in body weight, gross behaviors and avoidance learning between saline- and MAPpretreated groups. However, effects of MAP and apomorphine on the locomotor activity significantly increased in the MAP-pretreated group. Significant decreases in $B_{\max }$ and $K_{d}$ values of ${ }^{3} \mathrm{H}$-SPP binding sites in the striatum were detected in the MAP-pretreated group. while significant decreases in $B_{\max }$ values of ${ }^{3} \mathrm{H}$-WB4101 binding sites in the cortex and hippocampus as well as those in $K_{d}$ values in the hippocampus were found in the treated group. Dopamine and noradrenaline levels significantly decreased in the MAP-pretreated group, but on the contrary, their metabolites levels significantly increased. These results suggest that postnatal pretreatments with MAP produce long-lasting behavioral changes associated with an impaired development of catecholaminergic neurons in the rat brain after maturity.
\end{abstract}

It has been reported that prenatal (1-4) and early postnatal (5-10) pretreatments with psychotropic drugs frequently produced subsequent behavioral or biochemical changes in experimental animals after maturity. However, only few reports have been published concerning the effects of postnatal pretreatments with the drugs. We have, for this reason, investigated the effects of the pretreatments with several kinds of antipsychotic drugs $(5-10)$, alcohol, phenobarbital $(5,8,9)$ or diazepam (5). during an early postnatal period on behavioral or biochemical parameters in rats after maturity. Based on these investigations, we have reported that postnatal pretreatments with antipsychotic drugs, in particular, phenothiazine derivatives, alcohol or phenobarbital produced avoidance learning im- pairment, changes in susceptibility to psychotropic drugs or biochemical parameters after maturity.

The aim of the present experiment is to investigate the effects of postnatal pretreatments with methamphetamine on behaviors, catecholamine receptors and catecholamine levels in the rat brain.

\section{Materials and Methods}

\section{Animals and treatments}

One hundred-thirty male neonates obtained by 2 matings of 13 females with 6 male Wistar strain rats, which were supplied by the Institute of Experimental Animal Research of Gunma University School of Medicine, were used. Sixty-five rats were given s.c. several doses of methamphetamine $(1-4 \mathrm{mg} / \mathrm{kg})$, and the other 65 rats were 
given S.c. saline solution while they were kept with their mothers. Doses were made up to a volume of $10 \mathrm{ml} / \mathrm{kg}$ of body weight by diluting methamphetamine hydrochloride (MAP) (Philopon ${ }^{\mathbb{B}}$, Dainippon) with saline solution. The administration schedules were as follows: Groups I, II and 111 were given 1. 2 and $4 \mathrm{mg} / \mathrm{kg} / \mathrm{day}$ of MAP, respectively. for 7 successive days from 6 to 12 days of age. Groups IV-VI were prepared as controls for Groups I-III, respectively, and were given the same volume of saline solution.

Groups of 5 rats were housed in stainless steel wire mesh cages of $38(\mathrm{D}) \times 25(\mathrm{~W}) \times 20$ (H) $\mathrm{cm}$ after weaning at 21 days of age, and rats had free access to a solid diet of MF (Oriental Yeast Co., Tokyo) and tap water. The rats were kept in a room at $24 \pm 2^{\circ} \mathrm{C}$ with a $12 \mathrm{hr}$ light-dark cycle (fluorescent illumination on 7:00-19:00). MAP administration was conducted at 18:00 in all the groups. The body weights were recorded at 6,12 and 60 days of age, respectively. Measurement of the body weights and the avoidance test were performed in Groups 1-III, while the other behavioral and neurochemical investigations were done only for Group III.

\section{Discriminated lever-press avoidance schedule}

The acquisition of discriminated avoidance response was investigated beginning at 60 days of age. The rats were trained to avoid an electric shock by pressing a lever according to warning stimuli (buzzer and small lamp) presented in an operant chamber of 27 (D) $x$ $20(\mathrm{~W}) \times 18(\mathrm{H}) \mathrm{cm}$ (O'hara and Co. Ltd. Tokyo). The chamber was enclosed in a ventilated sound-attenuating box. The avoidance schedule consisted of a $25 \mathrm{sec}$ intertrial interval and a $5 \mathrm{sec}$ presentation of the warning stimuli. The electric shock of 110V, $0.5 \mathrm{~mA}, 50 \mathrm{~Hz}$ AC was delivered through the stainless steel floor grids. The maximum duration of shock presentation was $5 \mathrm{sec}$, because an escape contingency was allowed for in the schedule.

Each session consisted of $1 \mathrm{hr}$ training per day, and the training was held every other day for 15 sessions. The indicators for the evaluation of the acquisition processes were the response rate the number of lever pressings $/ \mathrm{min}$ ) and the avoidance rate (percent of correct response). The warm-up period data for the first $20 \mathrm{~min}$ of each session were excluded from the calculation of the mean avoidance and response rates in order to discard unstable responses (11). Effects of MAP and apomorphine on locomotor activity

MAP of $0.5 \mathrm{mg} / \mathrm{kg}$ and apomorphine (AMOR) of 0.05 or $0.5 \mathrm{mg} / \mathrm{kg}$ (apomorphine hydrochloride, Sigma Chemical Co.) were given s.c. to the rats at 100-120 days of age, and the locomotor activity was measured by the activity monitoring apparatus (Animex, type 5, Farad Co., Ltd., Sweden) which was enclosed in a sound-attenuating box. Each rat was placed in an activity cage (21(D) $x$ $34(\mathrm{~W}) \times 29(\mathrm{H}) \mathrm{cm})$ made of transparent plexiglas, and the cage was set on the monitoring apparatus. The activity counts were recorded automatically at $10 \mathrm{~min}$ intervals for $180 \mathrm{~min}$ in the case of MAP and $60 \mathrm{~min}$ in the case of AMOR. Administration of the drugs was conducted at 10:00-16:00 in all cases.

\section{Receptor assay}

${ }^{3} \mathrm{H}$-spiperone binding assay: The rats were killed by decapitation at 100-120 days of age, and brains were rapidly removed. Each brain was divided into 8 regions such as the cerebral cortex, striatum, hippocampus, hypothalamus, thalamus, midbrain, medulla oblongata/pons and cerebellum on an ice cold petri dish according to the method of Growinski and Iversen (12) with minor modifications. ${ }^{3} \mathrm{H}$-Spiperone (SPP) $(18 \mathrm{Ci} /$ mmol. Amersham Japan) binding tests to these regions were essentialy performed by the method of Usdin et al. (13). The reaction mixture $(1 \mathrm{ml})$ consisted of membrane suspension (about $0.5 \mathrm{mg}$ protein), ${ }^{3} \mathrm{H}$-SPP (final concentrations $0.11-2$ nM) $d$ butaclamol (final concentration of $1 \mu \mathrm{M}$, butaclamol hydrochloride, Research Biochemicals inc.) and ketanserin (final concentration of $0.1 \mu \mathrm{M}$. ketanserin tartrate, Kyowa Hakko). It is recommended to use ${ }^{3} \mathrm{H}$ SPP in $\mathrm{D}_{2}$-dopamine receptor binding studies in the presence of ketanserin, a $S_{2}$-serotonin blocker, because ${ }^{3} \mathrm{H}$-SPP simultaneously labels 5-HT receptors as well as dopamine receptors in the brain, particularly in the frontal cortex $(14,15)$. The mixture was incubated at $37^{\circ} \mathrm{C}$ for $20 \mathrm{~min}$, and then it was 
filtered through a Whatman GF/B filter under vacuum. The filter was rinsed three times with $5 \mathrm{ml}$ ice cold Tris- $\mathrm{HCl}$ buffer (50 $\mathrm{mM}, \mathrm{pH}=7.7$ ). The percent of specific binding of ${ }^{3} \mathrm{H}-\mathrm{SPP}$ to the total binding at 2 nM was $75-80 \%$.

${ }^{3} \mathrm{H}-$ WB4101 binding assay: ${ }^{3} \mathrm{H}-\mathrm{WB} 4101$, $\left\{2-\left(\left[2^{\prime}, 6^{\prime}\right.\right.\right.$-dimethoxy]phenoxyethylamino $)$ methyl benzodioxan\} (27 Ci/mmol. Amersham Japan) binding tests to the same 8 regions were performed by the method of U'Prichard et al. (16). The reaction mixture (1 $\mathrm{ml}$ ) consisted of membrane suspension (about $0.5 \mathrm{mg}$ protein). ${ }^{3} \mathrm{H}-\mathrm{WB} 4101$ (final concentrations $0.11-2 \mathrm{nM}$ ) and phentolamine (final concentration $0.5 \mathrm{mM}$, Regitin ${ }^{(}$, Japan Ciba-Geigy Ltd.). ${ }^{3} \mathrm{H}-$ WB4101 has been used as an $\alpha_{1}$-noradrenaline receptor marker in the brain (17). The mixture was incubated at $25^{\circ} \mathrm{C}$ for 20 min followed by filtration through a Whatman GF/B filter under vacuum. The filter was rinsed three times with $5 \mathrm{ml}$ ice cold Tris- $\mathrm{HCl}$ buffer $(50 \mathrm{mM}, \mathrm{pH}=7.7)$. Percent of specific binding of ${ }^{3} \mathrm{H}$-WB4101 to the total one at 2 n $\mathrm{M}$ was $57-63 \%$.

$\mathrm{K}_{\mathrm{a}}$ and $\mathrm{B}_{\max }$ values were determined by Scatchard analysis only for each case where significant differences in specific binding of ${ }^{3} \mathrm{H}$-SPP or ${ }^{3} \mathrm{H}$-WB4101 were observed between saline- and MAP-pretreated groups. Protein concentration was determined by the method of Lowry et al. (18).

\section{Catecholamine analysis}

The rats were decapitated at 100-120 days of age after enzyme inactivation by microwave irradiation at $5 \mathrm{~kW}$ for $1.5 \mathrm{sec}$ (Toshiba, Microwave Applicator, TMW6402A). Each brain was immediately removed for subsequent catecholamine analysis and dissected into the 8 regions as mentioned above. Regional levels of dopamine (DA). noradrenaline (NA) and DA metabolite, 3,4dihydroxyphenylacetic acid (DOPAC) were measured by high performance liquid chromatography with electrochemical detection (Yanaco, L-5000) according to the method of Keller et al. (19), while regional level of the NA metabolite, 3-methoxy-4hydroxy-phenylethyleneglycol (MHPG), was essentialy determined by the method of Semba and Takahashi (20). DA and DOPAC levels were determined only for the regions where significant difference in ${ }^{3} \mathrm{H}$-SPP specific binding was detected between saline- and MAP-pretreated groups, while NA and MHPG levels were determined only for the regions where significant difference in ${ }^{3} \mathrm{H}-$ WB 4101 specific binding was seen.

\section{Statistical analysis}

Differences between groups were assessed statistically by one way ANOVA followed by Student's $t$-test. They were considered sig nificant when the $P$ value was equal to or less than 0.05 .

\section{Results}

Body weights and gross behaviors: A significant difference was detected neither in body weights nor in gross behaviors between saline- and MAP-pretreated groups ( 1.2 and $4 \mathrm{mg} / \mathrm{kg} /$ day $\times 7$ days) during the MAP-treatment and thereafter.

Discriminated lever-press avoidance response: No significant difference in the acquisition processes of the avoidance response was observed between saline- and MAP-pretreated groups regardless of the pretreatment doses $(1,2$ and $4 \mathrm{mg} / \mathrm{kg} /$ day $\times 7$ days). The result obtained in Group 111 is represented in Fig. 1 as an example. Unstable and ineffective lever-pressings were often observed in several early sessions of the training, but the lever-pressings were stabilized by the 9th-10th sessions, and a stable behavioral baseline was almost established in both the groups. The avoidance rates reached $90-95 \%$ in the 9 th session. and this level was maintained thereafter in both the groups.

Effects of MAP and AMOR on locomotor activity: Figure 2 shows the effect of MAP $(0.5 \mathrm{mg} / \mathrm{kg})$ upon the locomotor activity in groups postnatally pretreated with saline and MAP of $4 \mathrm{mg} / \mathrm{kg} /$ day for 7 successive days. respectively. The locomotor activity in both the groups was accelerated for about $3 \mathrm{hr}$ with a maximum effect at $20 \mathrm{~min}$ after the drug administration. The activity in the MAPpretreated group was significantly higher than that in the saline-pretreated group at 50-60 and 90 min after the drug administration. However, no significant difference in the total activity for $3 \mathrm{hr}$ (saline-pretreated 
group: 2006.9 counts $/ 3 \mathrm{hr}$, MAP-pretreated group: 2719.5 counts $/ 3$ hr) was observed between these groups.

The locomotor activity in the same groups decreased below the preinjection level for about $1 \mathrm{hr}$ after $0.05 \mathrm{mg} / \mathrm{kg}$ of AMOR without appearance of any stereotyped behaviors, and no significant difference in the activity was detected between the groups (Fig. 3, left panel). However, the locomotor activity, in particular, horizontal movements in the saline-pretreated group was markedly accelerated accompanying continuous sniffing for about $1 \mathrm{hr}$ after the administration of $0.5 \mathrm{mg} / \mathrm{kg}$ of AMOR. The horizontal movements in the MAP-pretreated group, on the contrary, were scarcely seen after the same dose of AMOR. Moreover, stereotyped behaviors such as intense and continuous
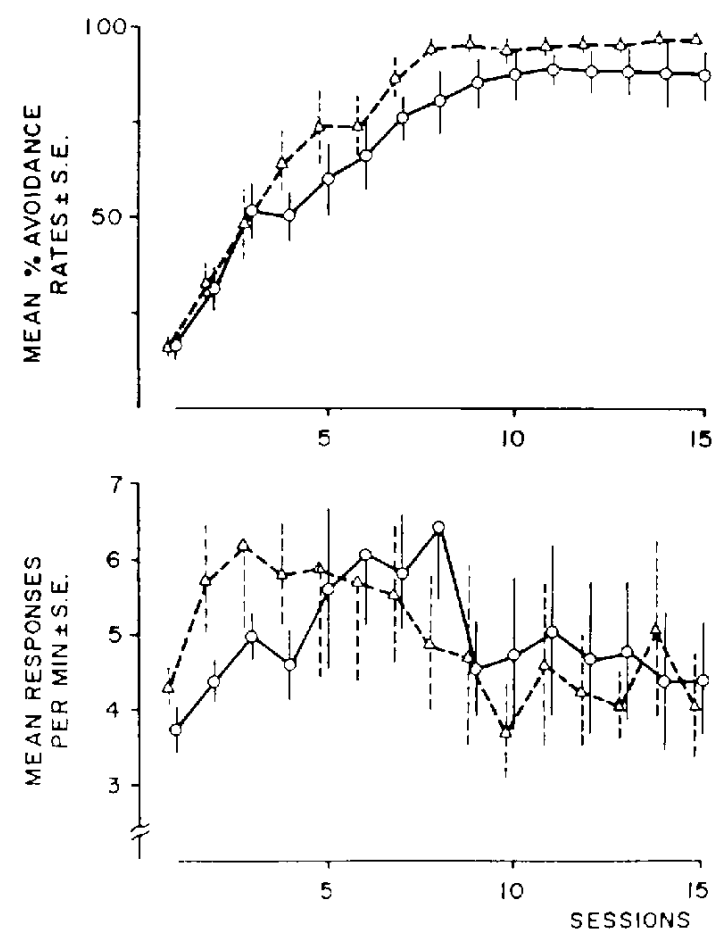

Fig. 1. Effect of postnatal pretreatment with methamphetamine on acquisition of conditioned avoidance response. The pretreatment produced no avoidance learning impaiment regardless of the doses pretreated. $\triangle$----- $\triangle$ Saline-pretreated group $(\mathrm{N}=10), \mathrm{O}-\mathrm{O}$ MAP-pretreated group $(\mathrm{N}=10)$ $(4 \mathrm{mg} / \mathrm{kg} / \mathrm{day} \times 7)$. Upper panel: Changes in avoidance rates. Lower panel: Changes in response rates. sniffing or licking markedly increased soon after the drug administration, and significant

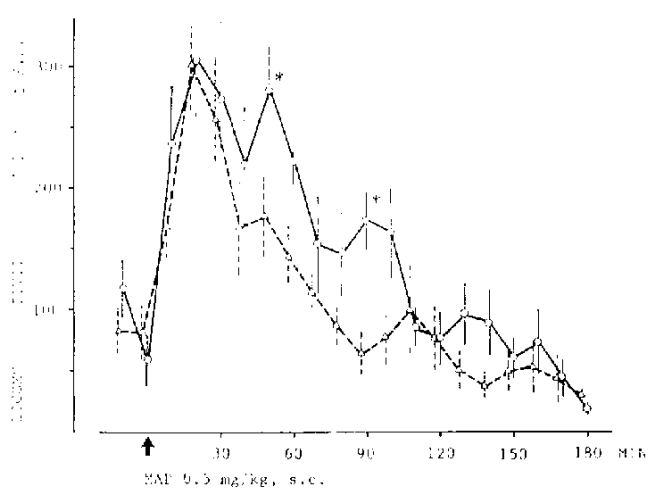

Fig. 2. Effect of methamphetamine $0.5 \mathrm{mg} / \mathrm{kg}$. s.c., on locomotor activity. Postnatal pretreatment with methamphetamine tended to increase the locomotor-accelerating effect of methamphetamine. $\triangle \cdots \cdots \triangle$ Saline-pretreated group $(N=8), O-O$ MAP-pretreated group $(\mathrm{N}=10)(4 \mathrm{mg} / \mathrm{kg} / \mathrm{day} \times 7)$. ${ }^{*} \mathrm{P}<0.05,{ }^{* *} \mathrm{P}<0.01$ vs, control.

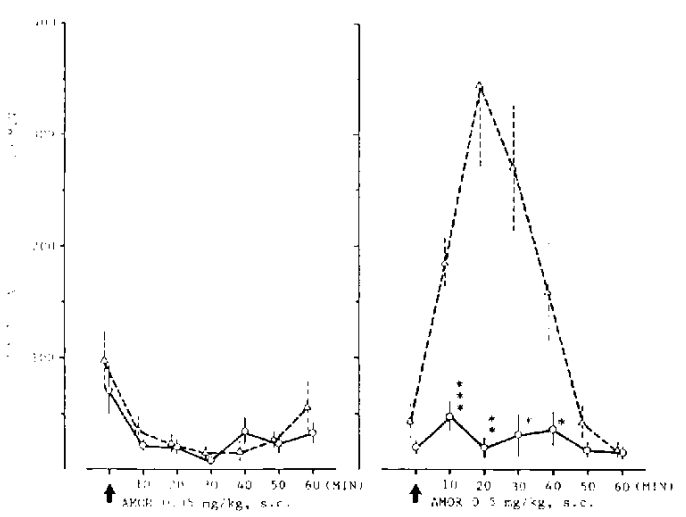

Fig. 3. Effect of apomorphine 0.05 (left panel) and $0.5 \mathrm{mg} / \mathrm{kg}$, s.c. (right panel), respectively on locomotor activity. Apomorphine of $0.05 \mathrm{mg} / \mathrm{kg}$ produced no difference in locomotor activity between the saline- and methamphetamine-pretieated groups. Apomorphine of $0.5 \mathrm{mg} / \mathrm{kg}$ accelerated markedly the activity in the saline-pretreated group which was accompanied by continuous sniffing, while the same dose caused marked stereotyped behaviors such as intense and continuous sniffing or licking in the methamphetamine-pretreated group and scarcely produced ambulatory movements. The data are shown in the same way as in Fig. 2. $\triangle$-.-- $\triangle$ Salinepretreated group $(\mathrm{N}=8), \mathrm{O}-\bigcirc \mathrm{MAP}$-pretreated group $(\mathrm{N}=8) \quad(4 \mathrm{mg} / \mathrm{kg} /$ day $\times 7) . \quad{ }^{*} \mathrm{P}<0.05$, ${ }^{* * P}<0.01$. ${ }^{* *} \mathrm{P}<0.001$ vs, control. 
Table 1. Effects of postnatal pretreatment with methamphetamine on saturation constants for specific bindings of ${ }^{3} \mathrm{H}$-spiperone and ${ }^{3} \mathrm{H}$-WB4101, respectively, in rat brain regions

\begin{tabular}{|c|c|c|c|c|}
\hline Ligands & Regions & Constants & $\begin{array}{c}\text { Saline-pretreated } \\
(1 \mathrm{ml} / \mathrm{kg} / \text { day } \times 7) \\
(N=4)\end{array}$ & $\begin{array}{c}\text { MAP-pretreated } \\
(4 \mathrm{mg} / \mathrm{kg} / \text { day } \times 7) \\
(N=4)\end{array}$ \\
\hline${ }^{3} \mathrm{H}$-Spiperone & Striatum & $\begin{array}{l}K_{1}(n M) \\
B_{\max } \\
\text { (fmol/mg protein) }\end{array}$ & $\begin{aligned} 0.23 & =0.01 \\
215.5 & \pm 8.7\end{aligned}$ & $\begin{array}{r}0.15 \pm 0.01^{* *} \\
161.6 \pm 3.1^{* * *}\end{array}$ \\
\hline${ }^{3} \mathrm{H}-$ WB 4101 & Hippocampus & $\begin{array}{l}\mathrm{K}_{\mathrm{d}} \\
\mathrm{B}_{\max } \\
\mathrm{K}_{\mathrm{dl}} \\
\mathrm{B}_{\max }\end{array}$ & $\begin{aligned} 0.42 & \pm 0.02 \\
206.8 & \pm 6.4 \\
1.78 & \pm 0.11 \\
407.7 & \pm 15.5\end{aligned}$ & $\begin{aligned} 0.47 & \pm 0.03 \\
182.1 & \pm 7.7^{*} \\
1.01 & \pm 0.05^{* *} \\
325.6 & \pm 7.2^{* *}\end{aligned}$ \\
\hline
\end{tabular}

${ }^{*} P<0.05,{ }^{*} P<0.01,{ }^{* *} P<0.001$ vs. control
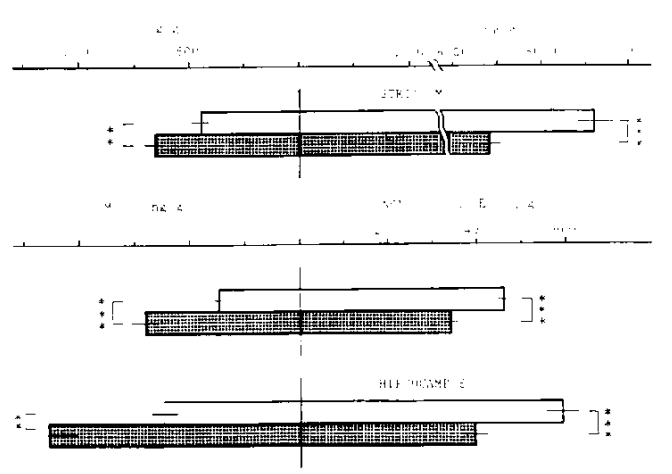

Fig. 4. Effect of postnatal pretreatment with methamphetamine on catecholamines and their metabolites levels in the rat brain. The pretreatment decreased the amine levels and increased the metabolite levels. White column: Saline-pretreated group ( $N=10)$. Hatched column: MAP-pretreated group $(N=10),{ }^{* *} P<0.01,{ }^{* *} P<0.001$ vs. control.

difference in the locomotor activity was found between the groups (Fig. 3, right panel).

Receptor binding: As shown in Table 1. significant differences in both $K_{d}$ and $B_{\max }$ values of ${ }^{3} \mathrm{H}$-SPP binding sites in the striatum were detected in the MAP-pretreated group as compared with the corresponding values obtained in the saline-pretreated group. Furthermore, significant decreases in $B_{\max }$ values of ${ }^{3} \mathrm{H}$-WB4101 binding sites in the cortex and hippocampus and significant decrease in the $K_{d}$ value of the binding site in the hippocampus were observed in the MAP-pretreated group as compared with the corresponding $B_{\max }$ and $K_{d}$ values obtained in the saline-pretreated group.
Catecholamine analysis: Significant decrease in dopamine level in the striatum and significant decreases in noradrenaline levels in the cortex and hippocampus, respectively, were found in the MAP-pretreated group as compared with the corresponding DA and NA levels obtained in the saline-pretreated group (Fig. 4). On the other hand, DOPAC levels significantly increased in the striatum, and MHPG levels significantly increased in the cortex and hippocampus in the MAPpretreated group as compared with the corresponding levels obtained in the salinepretreated group (Fig. 4).

\section{Discussion}

It is well-known that amphetamines easily pass through the blood-placental barrier and are distributed widely in the brain, liver and other organs of the mice fetus (21). It is also suggested that the drugs are metabolized more slowly in pregnant mice than in nonpregnant mice (21). In addition, postnatal development of the brain can be observed during the first 3-4 weeks after birth in rats or mice (22). It is, therefore, considered that MAP given during perinatal periods may produce long-lasting behavioral and neurochemical changes after maturity. Actually. changes in susceptibility to MAP or AMOR were observed in the present experiment.

Amphetamine induces release of both central and peripheral catecholamines and inhibits reuptake of the amines at the synaptic sites $(23,24)$. According to our experiences, MAP of $0.5 \mathrm{mg} / \mathrm{kg}$. s.c., is an optimum dose for acceleration of locomotor activity without 
producing any stereotyped behaviors in rats A small dose of AMOR is considered to stimulate the presynaptic dopamine receptor (25). while a large dose causes a stimulation of the postsynaptic receptor (26). Thus, AMOR shows multiphasic effects on locomotor activity in rats depending on the doses given. AMOR of $0.05 \mathrm{mg} / \mathrm{kg}, s . c$. decreases the activity accompanied by no stereotyped behaviors, while AMOR of 0.5 $\mathrm{mg} / \mathrm{kg}$, s.c., generally accelerates it markedly and sometimes produces stereotyped behaviors, in particular, sniffing. However. doses more than $0.5 \mathrm{mg} / \mathrm{kg}$, s.c., frequently cause strong stereotyped behaviors such as sniffing, rearing or licking and markedly decrease the ambulatory movements. Consequently, it is considered that the susceptibility to MAP and AMOR of $0.5 \mathrm{mg} / \mathrm{kg}$. s.C., in the MAP-pretreated group is stronger than that in the saline-pretreated group.

In the present experiment, marked decrease in the maximum density of $D_{2}$-binding sites $\left(B_{\max }\right)$ with an increase in the affinity $\left(1 / K_{d}\right)$ was observed in the striatum in the MAPpretreated group. A marked decrease in the density of $\alpha_{1}$-binding sites with an increase in the affinity was observed in the hippocampus. while only the decrease in the density of $\alpha_{1}$-binding sites was detected in the cortex in the MAP-pretreated group. In addition, marked decreases in brain catecholamine levels, and on the contrary. increases in their metabolites were observed in the same regions. The neurochemical data obtained in the present experiment. therefore. suggest that postnatal pretreatments with MAP produce long-lasting changes in $\mathrm{D}_{2}$ - or $\alpha_{1}$-binding sites and in the life cycle of catecholamines associated with the changes in susceptibility to MAP or AMOR.

It is reported that acceleration of locomotor activity or stereotyped behaviors is caused by stimulation of catecholaminergic neurons in the brain $(23,24)$. On the other hand, a number of reports have indicated that repeated administration of amphetamines produces an enhancement of the locomotion-increasing effect of the drugs in adult rats accompanying a decrease in dopamine binding sites (2731). Furthermore, the enhancement of the locomotion-increasing effect is reproduced by other catecholamine agonists such as AMOR (32), ephedrine (33), methylphenidate (34), etc. Based on these data, the development of subsensitivity of dopamine autoreceptors has been proposed as one of the possible mechanisms to account for the enhancement phenomenon. The enhancement of susceptibility to MAP or AMOR obtained in the present experiment, therefore, may be partially caused by an long-lasting increase in dopamine utilization which resulted from the subsensitivity of dopamine autoreceptors, although the mechanism underlying the enhancement may be so complex that our present findings indicate only a part of the neurochemical background. Further investigations on other neuronal systems responsible for this phenomenon are required.

It is reported that catecholaminergic neurons play an important role in avoidance learning (35). Previously, we reported that postnatal pretreatment with chlorpromazine produced marked avoidance learning impairment in adult rats (10). In these animals, the maximum density of $\alpha_{1}$-noradrenaline binding sites markedly decreased in the cortex, thalamus, hypothalamus, mid brain and oblongata/pons, but no change was seen in the $D_{2}$-dopamine binding sites. In the present experiment, no change in the acquisition processes of the avoidance learning was observed in MAP-pretreated animals, although changes in catecholaminergic neurons were also detected. This may be due to the regional specificity of the neurons in the avoidance learning. In addition to the catecholaminergic neurons, however, several kinds of neurons were reported to be involved in learning and memory (36). As yet, no details of the mechanism have been elucidated.

Prenatal treatments with amphetamine sometimes produced changes in general activity (37) or in learning ability in the offspring (38). In addition, it was reported that the pretreatments increased brain tyrosine hydroxylase activity, producing a higher turnover rate of tyrosine to catecholamines in the offspring (39). Furthermore, the pretreatments decreased brain nor- 
adrenaline levels, whereas they scarcely altered dopamine or serotonin leveis (40). In the present experiment, the effects of MAP on the fetus were not investigated. However. these data demonstrate many qualities in common with the MAP-induced behavioral or biochemical changes obtained in the present experiment, considering that the first 3-4 weeks after birth are vulnerable periods for the functional maturation of the rat brain.

It has been well-known that the psychotoxic effect of MAP is enhanced by repeated MAP-abuse and that "amphetamine psychosis" due to the enhancement of the effect is frequently produced (41). On the other hand. we have reported that the locomotionincreasing effect of MAP is enhanced progressively by repeated administration of the drug in mice or rats (42). This phenomenon is considered to be one of the useful models for the investigation of amphetamine psychosis (43). In the present experiment, it was suggested that postnatal pretreatments with MAP increased susceptibility to MAP after maturity. In addition. MAP-abuse is now one of the most serious drug-abuse problems. Much attention has to be paid to the effects of MAP on newborn infants or to those of MAP-abuse during pregnancy.

Acknowledgement: This research was supported in part by the Fund for Scientific Research from the Japanese Ministry of Welfare and Public Health.

\section{References}

1 Brown, R.M. and Fishman, R.H.B.: An overview and summary of the behavioral and neural consequences of perinatal exposure to psychotropic drugs. In Neurobehavioral Teratology, Edited by Yanai, J., p. 3-44, Elsevier Science Publishers BV. Amsterdam (1984)

2 Doty, B.A. and Doty, L.A.: Chiorpromazineproduced response decrements resulting from chronic administration in infancy. Can. J. Psychol. 17, 45-51 (1963)

3 Doty, L.A., Doty, B.A., Wise, M.A. and Senn, R.K: Effects of postnatal chlorpromazine on discrimination in rats. Percept. Mot. Skills 18, 329-332 (1964)

4 Young, R.D.: Effects of differential early experiences and neonatal tranquilization on later behavior. Psychol. Rep. 17, 675-680 (1965)
5 Hayashi, T. and Tadokoro, S.: Detection of behavioral abnormalities, especially learning impairment in rats, and its application to behavioral teratology. Cong. Anom. 20, 339358 (1980) (Abs. in English)

6 Hayashi, T. and Tadokoro, S.: Learning deficits produced by postnatal pretreatment with chlorpromazine in adult rats. Neurobehav. Toxicol. 3, 27-35 (1981)

7 Hayashi, T.: Learning deficit produced by postnatal pretreatments with antipsychotic drugs in adult rats. In Learning and Memory. Drugs as Reinforcer, Edited by Saito, S. and Yanagita, T., p. 3-21, Excerpta Medica. Amsterdam (1982)

8 Hayashi, T.: Behavioral changes produced by postnatal pretreatments with psychotropic drugs in adult rats. Especially, learning abnormalities. Japan. J. Neuropsychopharmacol. 2, 191-201 (1984) (in Japanese)

9 Hayashi, T. and Tadokoro, S.: Learning retardation and enhanced ethanol preference produced by postnatal pretreatments with ethancl in adult rats. Japan. J. Pharmacol. 37, 269-276 (1985)

10 Hayashi, T., Kunihara, M. and Tadokoro, S: Changes in ${ }^{3} \mathrm{H}$-spiperone. ${ }^{3} \mathrm{H}$-WB4101 and ${ }^{3} \mathrm{H}$ dihydroalprenolol bindings to brain membranes produced by postnatal pretreatment with chlorpromazine in adult rats. Japan. J. Pharmacol. 39, 45-50 (1985)

11 Hoffman, H.S., Fleshler, M. and Chorny, H.: Discriminated bar-press avoidance. J. Exp. Anal. Behav. 4, 309-316 (1961)

12 Growinski, J. and Iversen, L.L.: Regional studies of catecholamines in the rat brain-l. The disposition of ${ }^{3} \mathrm{H}$-dopamine and ${ }^{3} \mathrm{H}$-DOPA in various regions of the brain. J. Neurochem. 13 , $655-669$ (1966)

13 Usdin, T.B., Creese, I. and Snyder, S.H.: Regulation by cations of ${ }^{3} \mathrm{H}$-spiroperidol binding associated with dopamine receptors of rat brain. J. Neurochem. 34, 669-676 (1980)

14 Bischoff, S., Bittiger, H. and Krauss, J.: In vivo ${ }^{3} \mathrm{H}$-spiperone binding to the rat hippocampal formation: involvement of dopamine receptors. Eur. J. Pharmacol. 68, 305-315 (1980)

15 Mita, T., Kuno, T., Nakai, H. and Tanaka, C.: Evidence for the presence of $\mathrm{D}_{2}$ and $5-\mathrm{HT}_{2}$ receptors in the prefrontal cortex. Japan. J. Pharmacol. 32, 1027-1032 (1982)

16 U'Prichard, D.C., Greenberg, D.A. and Snyder, S.H.: Binding characteristics of a radiolabeld agonist and antagonist at central nervous system alpha noradrenergic receptors. Mol. Pharmacol. 13, 454-473 (1977) 
17 Williams, L.T. and Lefkowitz, R.J.: Identification and study of alpha-adrenergic receptors by radioligand binding techniques. In Receptor Binding Studies in Adrenergic Pharmacology. p. 53-82, Raven Press, New York (1978)

18 Lowry, D.H., Rosebrough, N.J., Farr, A.L. and Randall, R.J.: Protein measurement with Folin phenol reagent. J. Biol. Chem. 193, 265-275 (1951)

19 Keller, R., Oke, A., Mefford, I. and Adams, R.N.: Liquid chromatographic analysis of catecholamines routine assay for regional brain mapping. Life Sci. 19, 995-1004 (1976)

20 Semba, $J$, and Takahashi, R.: The effects of Lthreo-dihydroxyphenylserine on norepinephrine metabolism in rat brain. Psychiat. Res. 15, 319326 (1985)

21 Shah, N.S. and Yates, J.D.: Placental transfer and tissue distribution of dextroamphetamine in the mouse. Arch. Int. Pharmacodyn. Ther. 233, 200-208 (1978)

22 Nomura, Y.: Functional development of the synaptic transmission in the rat CNS and its interaction with drugs. Folia Pharmacol. Japon. 76, 413-427 (1980) (Abs. in English)

23 Heikkila, R.E., Orlansky, H., Mytilineou, C. and Cohen, G.: Amphetamine: Evaluation of $d$ - and I-isomers as releasing agents and uptake inhibitors for ${ }^{3} \mathrm{H}$-dopamine and ${ }^{3} \mathrm{H}$-norepinephrine in slices of rat neostriatum and cerebral cortex. J. Pharmacol. Exp. Ther. 194, 47-56 (1975)

24 Tyler. T.D. and Tessel, R.E.: Amphetamine's locomotor-stimulant and norepinephrinereleasing effects: Evidence for selective antagonism by nisoxetine. Psychopharmacology (Berlin) 64, 291-296 (1979)

25 DiChiara, G., Corsini, G.U., Mereu, G.P., Tissari, A. and Gessa, G.L.: Self-inhibitory dopamine receptors: Their role in the biochemical and behavioral effects of low doses of apomorphine. In Advances in Biochemical Pharmacology. Edited by Roberts, P.J., Vol. 19, p. 275-292, Raven Press, New York (1978)

26 Ernst, A.M.: Mode of action of apomorphine and dexamphetamine on gnawing compulsion in rats. Psychopharmacologia (Berlin) 10, 316323 (1967)

27 Hitzemann, R., Wu, J, Hom, D. and Loh, H.: Brain locations controlling the behavioral effects of chronic amphetamine intoxication. Psychopharmacology (Berlin) 72, 93-101 (1980)

28 Nielsen, E.B., Nielsen, M. and Braestrup, C.: Reduction of ${ }^{3} \mathrm{H}$-spiroperidol binding in rat striatum and frontal cortex by chronic amphetamine: Dose response, time course and role of sustained dopamine release. Psychopharmacology (Berlin) 81, 81-85 (1983)

29 Howlett, D.R. and Nahorski, S.R.: Acute and chronic amphetamine treatments modulate striatal dopamine receptor binding sites. Brain Res. 161, 173-178 (1979)

30 Kaneno, S. and Shimazono, Y.: Decreased in vivo ${ }^{3} \mathrm{H}$-spiroperidol binding in rat brain after repeated methamphetamine administration. Eur. J. Pharmacol. 72, 101-105 (1981)

31 Muller, P. and Seeman, P.: Presynaptic subsensitivity as a possible basis for sensitization by long-term dopamine mimetics. Eur. J. Pharmacol. 55, 149-157 (1979)

32 Kuribara, H. and Tadokoro, S.: Augmentation of sensitivity to ambulation-increasing effect of apomorphine induced by repeated administration in mice. Japan. J. Psychopharmacol. 4, 181-190 (1984)

33 Hirabayashi, M. and Okada, S.: Development of reverse tolerance to ambulation-increasing effect of ephedrine after repeated administration in mice. Japan. J. Psychopharmacol. 5, 231-241 (1985) (Abs. in English)

34 Hirabayashi, M., Okada, S., Mesaki, T. and Tadokoro, S.: Characteristics of reverse tolerance to ambulation-increasing effect of methylphenidate after repeated administration in mice. Japan. J. Psychopharmacal. 3, 117126 (1983) (Abs. in English)

35 Oei, T.P.S. and King, M.G.: Catecholamines and aversive learning: A review. Neurosci. Biobehav. Rev. 4, 161-173 (1980)

36 Squire, L.R.: Pharmacology of learning and memory. In Behavioral Pharmacology, Edited by Glick, S.D. and Goldfarb, J., p. 258-282, C.V. Mosby, Saint Louis (1976)

37 Bigl, V., Dalitz, E., Kunert, E., Biesold, D. and Leonard, B.E.: The effect of d-amphetamine and amitriptyline administered to pregnant rats on the locomotor activity and neurotransmitters of the offspring. Psychopharmacology (Berlin) 77. 371-375 (1982)

38 Nasello, A.G., Astrada, C.A. and Ramirez, O.A. Effects on the acquisition of conditioned avoidance response and seizure threshold in the effspring of amphetamine treated gravid rats. Psvchopharmacologia (Berlin) 40, 25-31 (1974)

39 Nasello, A.G. and Ramirez, O.A.: Brain catecholamines metabolism in offspring of amphetamine treated rats. Pharmacol. Biochem. Behav. 9, 17-20 (1978)

40 Hitzemann, B.A., Hitzemann, R.J., Brase, D.A. 
and Loh, H.H.: Influence of prenatal damphetamine administration on development and behavior of rats. Life Sci. 18, 605-612 (1976)

41 Ellinwood, E.H., Sudilovsky, A. and Nilson, L.M.: Evolving behavior in the clinical and experimental amphetamine (model) psychosis. Am. J. Psychiatry 130, 1088-1093 (1973)

42 Hayashi, T. and Tadokoro, S.: Reverse tolerance produced by repeated administration of psychotropic drugs, in particular methamphetamine in mice and rats as well as changes in catecholamine receptors. Metabolism and Disease 22, 37-47 (1985) (in Japanese)

43 Kato, N.: Methamphetamine psychosis and schizophrenia-Clinical and biochemical correlations. Adv. Neurol. Sci. 29, 950-963 (1985) 